\title{
An Analysis of the Cost Structure of Food Industries in Pakistan: An Application of the Translog Cost Function
}

\author{
Sajid Hussain, ${ }^{*}$ Uzma Nisar $^{* *}$ and Waseem Akram ${ }^{* * *}$
}

\begin{abstract}
Given the importance of food industries in Pakistan, this study analyzes their cost structure by estimating the transcendental logarithmic cost function. The study also considers elasticity of substitution along with own-price elasticity and cross-price elasticity. Four factor inputs, i.e., labor, capital, energy, and materials, are used to estimate the cost function. The results indicate that materials account for the highest share of the cost. The elasticity of substitution of materials for capital and energy is also weak. The own-price elasticities indicate that the demand for materials is least responsive to a change in its own price while the demand for other inputs varies with price. The cross-price elasticities show that labor, capital and energy are substitutes for each other. The output elasticity of cost demonstrates the presence of economies of scale.
\end{abstract}

Keywords: Translog cost function, elasticity of substitution, cross-price elasticity, Allen's partial elasticity.

\section{JEL Classification: D24, Q11.}

\section{Introduction}

Pakistan's manufacturing sector plays an important role in the country's economic development, having contributed 13.5-13.8 percent to GDP during the last decade. Large-scale manufacturing has a 78 percent share in manufacturing and a 10.2 percent share in GDP. The foodprocessing sector contributes 12.37 percent of the total gross value addition of large-scale manufacturing (Pakistan, Ministry of Finance, 2019). Along with value addition, this sector also procures and processes enough food to meet the demand of the country. This makes it essential to identify the underlying factors involved in food production so that the social planners

\footnotetext{
* MPhil Scholar, Department of Economics, The University of Lahore, Sargodha Campus. hsajid0067@gmail.com

** Lecturer, Department of Economics, The University of Lahore, Sargodha Campus. uzmanisar28@gmail.com

*** Lecturer, Department of Economics, The University of Lahore, Sargodha Campus. cwa555@gmail.com
} 
can find a balance among the factor inputs-such as labor, capital and energy - required. It is also important from the perspective of a developing country with an abundance of labor and a dearth of capital.

A better understanding of the food sector's cost structure can help reduce the cost of production and maximize output. Input price responsiveness and substitutability among inputs can also enable a better understanding of the optimal factor inputs. Accordingly, this study analyzes the cost structure of food industries in Pakistan and computes the elasticities of substitution among factor inputs, own-price elasticities, and cross-price elasticities.

Single-output production functions can take a variety of functional forms. The most widely used is the Cobb-Douglas production function, which works under certain restrictions: it is homogeneous of degree 1 and elasticities of substitutions (ES) are restricted to 1. ES measures the percentage change in factor proportions due to a one-percent change in their relative prices (Banda \& Verdugo, 2007). In contrast, the constant elasticity of substitution (CES) production function allows the elasticity of substitution to vary between 0 and infinity. However, the ES remains constant at various levels of outputs and inputs.

A difficulty in using CES is that we cannot compute the ES for more than two inputs (McFadden, 1963). Diewert (1971) introduced a functional form that incorporates $\mathrm{N}$ inputs and permits the ES to change at varying levels of inputs. Christensen, Jorgenson and Lau (1973) developed a more flexible functional form known as the translog production function. This allows many inputs and varying ES for different combinations of inputs and imposes no prior restrictions on the function. It is possible to compute homogeneity, homotheticity, CES, and variable elasticity of substitution (VES) using the translog function through appropriate restrictions. We have therefore analyzed cost structure by estimating the translog cost function for Pakistan's food industry. The findings indicate that materials have the highest share in the cost structure. The ES of material for labor and for capital is also low. The own-price elasticities indicate that the demand for materials is least responsive to a change in its own price, while demand for other inputs varies with price. The cross-price elasticities show that labor, capital and energy are substitutes for each other. The output elasticity of cost demonstrates the presence of economies of scale.

The rest of the article proceeds as follows: Section 2 discusses relevant studies in the literature and their findings. Section 3 describes the 
methods used to estimate the translog cost function and different types of elasticities. It also discusses the data and defines the variables used for the analysis. Section 4 presents and discusses the study's results. Section 5 concludes the study and discusses policy implications.

\section{Literature Review}

Costantini and Paglialunga (2014) conduct a comprehensive study of the cost structure of 10 manufacturing sectors in 21 OECD economies. The study aims to probe the factors affecting cost and focuses on measuring energy-output and capital-energy substitution over the period 1970-2008. They employ the translog production (KLEM) function and compute Allen elasticity of substitution (AES) for different subperiods to analyze the transition over time. The capital-energy substitution is lower than 1 and differs by sector. It remains consistent in subperiods for the food sector only, while the textiles (0.44 and 0.47) and wood sectors (0.13 and 0.16) increase over time. Some industries follow U-shaped trends over time.

Berndt and Wood (1975) study the possibility of substitution between energy and nonenergy inputs in US manufacturing. The translog cost function is estimated using time-series data (1947-71). They use an iterative three-stage least squares estimator. Own-price and cross-price elasticity are also estimated for energy. The results indicate that energy is own-price-elastic $(-0.47)$, and that energy and labor are slightly substitutable (0.65). The crossprice elasticity between energy and labor, and labor and capital, is relatively small (0.18 and 0.05 , respectively). It is evident that energy and capital are complementary since the elasticity of substitution is -3.2. Krishnapillai and Thompson (2012) also study the translog production function for the US manufacturing industry. They estimate own-price elasticity, cross-price elasticity, and Morishma elasticity of substitution using cross-section data for 2007. The study finds that capital, labor, and electricity are substitutes for each other, but electricity is a weaker substitute for labor and capital, and labor and capital are stronger substitutes for electricity. Erickson et al. (2003) estimate the US agriculture sector's translog cost function. The study uses time-series data to estimate static and dynamic functions. The short-run and long-run cost functions are estimated using concentrated maximum likelihood estimation. The AES is computed to determine substitutability. For inputs and capital, capital and labor, and inputs and labor, the AES is $0.52,-0.58$ and 0.489 , respectively. The study concludes that static long-run results are not consistent with the concavity restriction, while the dynamic model obeys production theory. 
The translog cost function for Mexican manufacturing is estimated by Banda and Verdugo (2007), who compute own-price elasticity, crossprice elasticity and the ES of input demand. They also estimate economies of scale and the average cost function. The study uses the full information maximum likelihood method to analyze cross-section data for three different years (1996, 2000, and 2003), based on four inputs-labor, capital, electricity and transport. The Allen-Uzawa elasticity is estimated to check for substitutability among inputs. The study concludes that there are substitutable alternatives between considered inputs. Sterner (1989) also examines ES and factor demand for the Mexican manufacturing industry. The study uses data for a four-yearly census for 1968-81, which covers all the major industries. The average price elasticity of capital $(-0.2)$ and material $(-0.3)$ are least elastic among the five inputs, while the value is more elastic for labor $(-0.5)$, fuel $(-0.6)$, and electricity $(-0.4)$.

Abdullah and Osman-Rani (1989) measure the AES using the translog cost function. The AES is calculated at mean-cost-share. The study's primary objective is to estimate the ES between labor and capital in the Malaysian manufacturing industry. A study to compute the ES for the years 1968, 1989, and 1984 shows that there is limited evidence of substitutability between labor and capital for Malaysian manufacturing industries.

Khalil (2005) estimates the translog cost function for the Jordanian manufacturing industry, using cross-sectional data for 2002. The study utilizes cost-shares, factor inputs, factor prices, and output and uses the iterative Zellner-efficient technique to achieve its objective. The results show that the Allen partial ES is constant but significant. The substitutability between capital and materials and between labor and materials is less than the substitutability for capital-labor. Heshmati and Haouas (2013) investigate scale economies in Tunisian industries, using time-series data and considering the restriction of increasing returns to scale and imperfect competition. Estimating a translog cost function, their results indicate that most industrial sectors have increasing returns to scale.

Kemal (1981) computes the ES between labor and capital for Pakistan's manufacturing sector. This study employs data from the Census of Manufacturing Industries (CMI) for Pakistan. The iterative maximum likelihood technique is used to calculate estimates. The ES between capital and labor is limited in most industries when computed through the VES model, and is significant for only three of sixteen industries in the case of the CES model. The study also provides a comparison of ES among the manufacturing sectors of different countries. The ES for Argentina's 
manufacturing sector is lower than that of Pakistan, while the ES for Chile and Israel is higher.

Chishti and Mahmood (1991) estimate energy demand for the industrial sector in Pakistan, including price and substitution elasticities between energy and nonenergy inputs. The study uses aggregate-level data for 1960-80. The translog production function is estimated using Zellner's iterative procedure for the cost equation. The results show that the ES between energy and employment is high, while the substitutability between employment and capital is limited. The ES between energy and capital is negative. These results indicate that the higher price of energy negatively affects investment in capital goods.

Zafar and Ahmed (2005) discuss allocative efficiency and ES in the manufacturing sector in Pakistan. They focus on the sector's cost structure and employ the translog cost function, using the CMI. The study uses the iterative Zellner-efficient technique to compute the parameters, and finds that raw materials contribute 85 percent to total cost. The results further indicate that the intensity of labor use decreases as the level of output increases, whereas this is not true for capital and raw material. The elasticities show that labor and raw material are substitutes while labor and capital have a complementary relationship.

Mahmood, Ghani and Din (2006) investigate the efficiency of largescale manufacturing industries in Pakistan, using cross-sectional data for 1995/96 and 2000/01 and applying the stochastic production frontier approach. The results show that most industrial groups gained technical efficiency while some industries faced a deterioration in efficiency. Several factors may have caused this decline in firms' technical efficiency, including external competition and the trade policy environment.

The literature review above discusses studies on the agriculture and industrial sectors of different countries. Meta-analyses, like Costantini and Paglialunga (2014) for 21 OECD economies, and another by Berndt and Wood (1975) show weaker substitutability between energy and capital and between energy and labor. Similarly, Krishnapillai and Thompson (2012) have shown that electricity is a weaker substitute for labor and capital. In the case of the US agriculture sector, Erickson et al. (2003) demonstrate complementarity between capital and labor. Abdullah and Osman-Rani (1989) show limited capital and labor substitutability for Malaysia's industrial sector. For the Jordanian economy, Khalil (2005) finds relatively 
greater substitutability between labor and capital than between labor and material, and capital and material.

Like other developing countries, Pakistan has scarce capital and materials, but abundant labor (Zafar \& Ahmed, 2005), and inadequate energy. Rushdi (1982) focuses on material and energy in a study of ES. ES has an interesting relationship with the type of data used to compute it-time-series data always yields a lower value than cross-section data (Kemal, 1981). This could be a result of cyclical phenomena and simultaneity between inputs and outputs (Kemal, 1981), while the ES between capital and labor remains limited (Diwan \& Gujarati, 1968; U. A. Kazi, 1980). Zafar and Ahmed (2005) find a negative ES between labor and capital. However, this was statistically insignificant.

Studies on Pakistan's industrial sector by Kemal (1981) and Zafar and Ahmed (2005) show limited substitutability between labor and capital, while Chishti and Mahmood (1991) find a stronger ES between energy and employment.

Battese and Malik (1987) estimate the ES for selected manufacturing industries in Pakistan and compare their estimates with those of previous studies, claiming that their weighted least squares analysis yields more precise results of elasticities than S. Kazi et al. (1976) and Kazmi (1981), as both these studies use ordinary least squares (OLS) regression. Battese and Malik (1987) estimate that the ES between labor and capital is 1.31 for all industries. A further classified analysis shows that the ES for food industries is 1.38, assuming constant returns to scale (CRS). Thus, the literature suggests that the substitutability between labor and capital is not as strong in Pakistan's food processing industries.

\section{Data and Methodology}

This section describes the data and variable used and specifies the estimation model.

\subsection{Data and Variables}

The data used was obtained from the Pakistan Bureau of Statistics, specifically the five-yearly CMI. We have used the CMI 2005/06 for data for the food, beverages and tobacco sectors. The CMI provides microdata on all industrial units within these sectors. 
The variables used are the price of labor, the price of capital, the price of energy, the price of material, and total output. Capital comprises total land area, dwellings, structures other than dwellings (buildings for machinery installation, etc.), machinery and equipment, and intellectual property as of 30 June every year. Depreciation is deducted from gross capital to calculate net capital. The total cost of capital is the sum of depreciation and opportunity cost. The opportunity cost is the best alternative forgone, which is considered the loss of interest earned. The CMI 2005/06 provides the amount of net capital as on 1 July 2005. The cost of capital or the price of capital $\left(P_{k}\right)$ is computed using the following formulation:

$$
C_{k}=K *(r+\delta)
$$

where $\mathrm{K}$ is the amount of capital, $r$ is the real interest rate, and $\delta$ is the rate of depreciation. The real interest rate for 2005/06 was 1.91 percent (Pakistan, Ministry of Finance, 2006). The CMI 2005/06 also provides the amount of depreciation, but about 45 percent of the observations are missing. Therefore, we calculate the amount of depreciation for different capital goods at the prescribed rates. The Federal Board of Revenue (2014) provides the rates of depreciation for different types of assets (Table 1).

Table 1: Rate of asset depreciation

\begin{tabular}{lccc}
\hline $\begin{array}{l}\text { Machinery and } \\
\text { equipment }\end{array}$ & Buildings & Furniture & Office equipment \\
\hline $15 \%$ & $10 \%$ & $15 \%$ & $30 \%$ \\
\hline
\end{tabular}

After calculating depreciation, the total user cost of capital is calculated using equation (1). The per-unit cost of capital is calculated by dividing the total user cost of capital by the total amount of capital:

$$
P_{k}=C_{k} / K
$$

Energy represents the consumption of gas, fuels and electricity by a firm during the year 2005/06. The CMI 2005/06 provides information on quantities used and expenditures made on petrol, diesel, gas and electricity separately. Since the energy used by firms falls under different categories and units of measurement, the price of each category of energy fuel is calculated by dividing cost by quantity. For the translog cost function, one price index is required. This price index is calculated through the weighted price of each energy type. The individual price is weighted by share of cost: 


$$
P_{e}=\sum P_{e i} * S_{e j} \quad i=j
$$

where P, C, and S represent price, cost, and share of cost for petrol, diesel, gas, electricity, and other.

Material includes all inputs and raw material used during the year 2005/06. The variable is constructed similarly on the basis of cost-shares. Different materials with varying units of measurement are not weighted equally. Since the per-unit prices of a material with the lowest share of the total material cost and a material with a larger share of cost are not equally important, the price of each material input is weighted by its share of the total material cost:

$$
P_{m}=\sum P_{m i} * S_{m j} i=j
$$

Labor comprises regular employees, casual employees, contractual employees, family members, and partners. Labor cost is the sum of all payments to these workers.

The CMI 2005/06 dataset contains information on the total number of days a firm operated, the average number of shifts per day, and the average number of employees differentiated by gender and by categoryproduction workers, nonproduction workers, unpaid/paid family members, and active partners-for every production unit. This information is provided quarterly. The payment made against labor is annual and categorized by wages and salaries, other cash payments and payments in kind, and by labor type (production workers, nonproduction workers, unpaid/paid family members, and active partners).

The CMI 2005/06 segregates output into two categories: (i) main production activities and (ii) other activities. The dataset provides the value of production during FY2005/06 for each product.

\subsection{Model Specification and Estimation}

Our objective is to estimate cost as a function of factor prices and output. Both factor prices and output have a direct effect on total cost. The functional relationship is given below:

$$
C=c\left(P_{i}, Q\right), i=\mathrm{K}, \mathrm{L}, \mathrm{E}, \mathrm{M}
$$


Various functional forms have been developed to estimate the cost function. The functional form most commonly used is the transcendental logarithmic (translog) form developed by Christensen et al. (1973), which we use here for its flexibility and ease of computation.

The KLEM model is given below:

$$
\begin{aligned}
& \ln C=a_{0}+a_{q} \ln Q+a_{k} \ln P_{k}+a_{l} \ln P_{l}+a_{e} \ln P_{e}+a_{m} \ln P_{m}+1 / 2 a_{q q}(\ln Q)^{2}+1 / 2 a_{k k}\left(\ln P_{k}\right)^{2} \\
& +1 / 2 a_{l l}\left(\ln P_{l}\right)^{2}+1 / 2 a_{e e}\left(\ln P_{e}\right)^{2}+1 / 2 a_{m m}\left(\ln P_{m}\right)^{2}+1 / 2 \gamma_{k l} \ln P_{k} \ln P_{l}+1 / 2 \gamma_{k e} \ln P_{k} \ln P_{e} \\
& +1 / 2 \gamma_{k m} \ln P_{k} \ln P_{m}+1 / 2 \gamma_{l e} \ln P_{l} \ln P_{e}+1 / 2 \gamma_{l m} \ln P_{l} \ln P_{m}+1 / 2 \gamma_{e m} \ln P_{e} \ln P_{m} \\
& +\gamma_{q k} \ln Q \ln P_{k}+\gamma_{q l} \ln Q \ln P_{l}+\gamma_{q e} \ln Q \ln P_{e}+\gamma_{q m} \ln Q \ln P_{m}
\end{aligned}
$$

$\mathrm{C}, \mathrm{Q}, \mathrm{K}, \mathrm{L}, \mathrm{E}$, and $\mathrm{M}$ are cost, output, capital, labor, energy, and material, respectively, while the $\alpha$ and $\gamma$ terms are the parameters of the model. To estimate these parameters, we impose symmetry and linearity restrictions on the model. According to Young's theorem, cross-partial derivatives are always equal.

$$
\frac{\partial C}{\partial P_{i} \partial P_{j}}=\frac{\partial C}{\partial P_{j} \partial P_{i}}, i j=\mathrm{K}, \mathrm{L}, \mathrm{E}, \mathrm{M}
$$

Linear homogeneity restrictions are imposed on equation (6) (Berndt \& Wood, 1975) as follows:

$$
\begin{aligned}
& \alpha_{k}+\alpha_{l}+\alpha_{e}+\alpha_{m}=1 \\
& \gamma_{k k}+\gamma_{k l}+\gamma_{k e}+\gamma_{k m}=0 \\
& \gamma_{l l}+\gamma_{l k}+\gamma_{l e}+\gamma_{l m}=0 \\
& \gamma_{e e}+\gamma_{e l}+\gamma_{e k}+\gamma_{e m}=0 \\
& \gamma_{m m}+\gamma_{m l}+\gamma_{m k}+\gamma_{m e}=0
\end{aligned}
$$

Closely following Banda and Verdugo (2007), the following models are estimated and tested for the significance for each category: (i) unrestricted model, (ii) homothetic cost model, (iii) homogeneous cost model, and (iv) CRS model. Next, we estimate models A1, B1 C1, and D1 by imposing a unitary ES restriction on models A, B, C, and D.

A number of other restrictions can be imposed on the translog cost function to identify the function's form. This applies whether the function is 
unrestricted, homothetic, homogeneous in output, or CRS. If a cost function is written as a separable function of factor prices and output, it is termed a homothetic cost function. The necessary and sufficient condition for homotheticity is:

$$
\gamma_{q i}=0
$$

A homothetic cost function becomes homogeneous in output if the cost elasticity of output is invariant of production. For estimation purposes, we impose the following restriction:

$$
\gamma_{q q}=0
$$

When a homogeneous cost function is further restricted with $\alpha_{q}=1$, it becomes a CRS model. The translog cost function reduces to a CobbDouglas function when the CRS is subject to the following restriction:

$$
\gamma_{i j}=0
$$

The factor share equation $S_{i}$ is the partial derivative for each factor input (Shephard's lemma). The sum of the shares is 1.

$$
\begin{aligned}
& \frac{\delta \ln C}{\delta \ln P_{k}}=S_{k}=\alpha_{k}+\gamma_{q k} \ln Q+\gamma_{k k} \ln P_{k}+\gamma_{k l} \ln P_{l}+\gamma_{k e} \ln P_{e}+\gamma_{k m} \ln P_{m}+\varepsilon_{k} \\
& \frac{\delta \ln C}{\delta \ln P_{l}}=S_{l}=\alpha_{l}+\gamma_{q l} \ln Q+\gamma_{l k} \ln P_{k}+\gamma_{l l} \ln P_{l}+\gamma_{l e} \ln P_{e}+\gamma_{l m} \ln P_{m}+\varepsilon_{l} \\
& \frac{\delta \ln C}{\delta \ln P_{e}}=S_{e}=\alpha_{e}+\gamma_{q e} \ln Q+\gamma_{e k} \ln P_{k}+\gamma_{e l} \ln P_{l}+\gamma_{e e} \ln P_{e}+\gamma_{e m} \ln P_{m}+\varepsilon_{e} \\
& \frac{\delta \ln C}{\delta \ln P_{m}}=S_{m}=\alpha_{m}+\gamma_{q m} \ln Q+\gamma_{m k} \ln P_{k}+\gamma_{m l} \ln P_{l}+\gamma_{m e} \ln P_{e}+\gamma_{m m} \ln P_{m}+\varepsilon_{m}
\end{aligned}
$$

We compute the Allen partial ES between inputs $i$ and $j$ using Uzawa's (1962) formulation. These are necessary to analyze the degree of substitutability and complementarity between inputs, and are computed as follows: 
$\sigma_{i j}=\frac{\gamma_{i j}}{S_{i} S_{j}}+1$

Own-price and cross-price elasticities can be calculated using the following construction:

$$
\begin{aligned}
& \eta_{i i}=\frac{\gamma_{i i}}{S_{i}} S_{i}-1 \\
& \eta_{i j}=\frac{\gamma_{i j}}{S_{i}} S_{j} \text { and } i \neq j
\end{aligned}
$$

The cost elasticity of output is the percentage change in the cost of production in response to a one-percent change in output. It is computed as a partial derivative of the translog cost function for output:

$$
\frac{\delta \ln C}{\delta \ln q}=a_{q}+\gamma_{q q} \ln Q+\sum \gamma_{q i} \ln P_{i}
$$

It is not possible to estimate the overall model because it yields biased estimates due to the multicollinearity problem. This problem can, however, be resolved through shared equations (12-15). The joint estimation of shared equations along with the general model cannot be carried out using OLS, and therefore, we use Zellner's iterative technique (Banda \& Verdugo, 2007). Since the sum of shares is 1 , the problem of singularity arises (Zafar \& Ahmed, 2005). This difficulty is resolved by dropping one of the share equations (Christensen et al., 1973) and using only $\mathrm{N}-1$ share equations in the estimation (Barten, 1969; Kmenta \& Gilbert, 1968). Zellner's iterative estimates are invariant to which equation is dropped (Barten, 1969).

Among these eight models, one best-fit model is selected using Akaike's information criterion (AIC) and the Bayesian information criterion (BIC). A model that produces fewer AIC indices is likely to be an adequate best-fit model (Everitt, 1998). The index is computed as follows:

$$
A I C=-2 L_{m}+2 m
$$

where $m$ represents the number of parameters in the model and $L_{m}$ is the maximized log likelihood value. 
Next, we calculate the bordered Hessian determinant. A wellbehaved translog cost function must be concave. The cost function's concavity requires the bordered Hessian determinant to be negative semidefinite, while all estimated cost-shares must be positive. One of the limitations of the translog cost function is that it cannot assure global concavity. The formulation of the bordered Hessian determinant is given below (Segal, 2003):

$$
|H|=\left[\begin{array}{ccccc}
0 & \frac{S_{k}}{P_{k}} & \frac{S_{l}}{P_{l}} & \frac{S_{e}}{P_{e}} & \frac{S_{m}}{P_{m}} \\
\frac{S_{k}}{P_{k}} & \frac{1}{P_{k}^{2}\left(\gamma_{k k}+S_{k}\left(S_{k}-1\right)\right)} & \frac{1}{P_{k} P_{l}\left(\gamma_{k l}+S_{k} S_{l}\right)} & \frac{1}{P_{k} P_{e}\left(\gamma_{k e}+S_{k} S_{e}\right)} & \frac{1}{P_{k} P_{m}\left(\gamma_{k m}+S_{k} S_{m}\right)} \\
\frac{S_{l}}{P_{l}} & \frac{1}{P_{k} P_{l}\left(\gamma_{k l}+S_{k} S_{l}\right)} & \frac{1}{P_{l}^{2}\left(\gamma_{l l}+S_{l}\left(S_{l}-1\right)\right)} & \frac{1}{P_{l} P_{e}\left(\gamma_{l e}+S_{l} S_{e}\right)} & \frac{1}{P_{m} P_{l}\left(\gamma_{m l}+S_{m} S_{l}\right)} \\
\frac{S_{e}}{P_{e}} & \frac{1}{P_{k} P_{e}\left(\gamma_{k e}+S_{k} S_{e}\right)} & \frac{1}{P_{l} P_{e}\left(\gamma_{l e}+S_{l} S_{e}\right)} & \frac{1}{P_{e}^{2}\left(\gamma_{e e}+S_{e}\left(S_{e}-1\right)\right)} & \frac{1}{P_{m} P_{e}\left(\gamma_{m e}+S_{m} S_{e}\right)} \\
\frac{S_{m}}{P_{m}} & \frac{1}{P_{k} P_{m}\left(\gamma_{k m}+S_{k} S_{m}\right)} & \frac{1}{P_{m} P_{l}\left(\gamma_{m l}+S_{m} S_{l}\right)} & \frac{1}{P_{m} P_{e}\left(\gamma_{m e}+S_{m} S_{e}\right)} & \frac{1}{P_{m}^{2}\left(\gamma_{m m}+S_{m}\left(S_{m}-1\right)\right)}
\end{array}\right]
$$

\subsubsection{Zellner's Iterative Estimation Technique}

Using OLS, a single equation can be estimated efficiently, but it produces inefficient and biased results for a system of equations. Zellner developed a procedure to estimate a system of equations in 1962, based on Aitken's generalized least squares and is asymptotically efficient. The procedure can be applied to microdata, cross-section data, and timeseries data.

Suppose we have $\mathrm{M}$ equations and $\mathrm{T}$ observations. This can be written in equation form as:

$Y_{m}=X_{u} b_{u}+\mu_{u}$

The matrix form is given below.

$\left[\begin{array}{c}Y_{1} \\ Y_{2} \\ \vdots \\ Y_{m}\end{array}\right]=\left[\begin{array}{ccc}X_{1} & 0 & 0 \\ 0 & X_{2} & 0 \\ \vdots & \vdots & \vdots \\ 0 & 0 & X_{m}\end{array}\right]\left[\begin{array}{c}b_{1} \\ b_{2} \\ \vdots \\ b_{m}\end{array}\right]+\left[\begin{array}{c}\mu_{1} \\ \mu_{2} \\ \vdots \\ \mu_{m}\end{array}\right]$

The disturbance is an MT $\times 1$ matrix, which is computed as: 


$$
\sum=\sum_{C} \otimes I
$$

where $\Sigma$ represents the variance-covariance matrix of the disturbance vector, $\Sigma_{c}$ is the variance matrix, and I represents a unit matrix of $\mathrm{T} \times \mathrm{T}$ order. $\mathrm{T}$ represents time in the time-series data and assumes no autocorrelation between disturbance terms. In cross-sectional data, $T$ represents the number of observations and follows the same assumptions.

The estimation procedure uses weighted deviations. In the presence of heteroskedasticity, this weights the square of each deviation by the reciprocal of its variance instead of giving equal weights as in the case of OLS. In simple words, observations with a higher variance are given lower weights. Therefore, this procedure generates asymptotically efficient results.

\section{Results and Discussion}

The total number of observations is 1,710 . The mean cost-share of labor, capital, energy, and material is 0.031, 0.026, 0.043, and 0.90, respectively. Material has the largest share of total cost and the share of capital is smallest. Manufacturers of cotton linter appear most frequently (540) in the dataset. The cost-share relationship with output for all input prices is presented in Figure 1 (see also Table 2). The cost-share of labor, capital and energy fall as production rises. Conversely, the cost-share of material increases as output rises.

Figure 1: Cost-shares of labor, capital, energy, and material
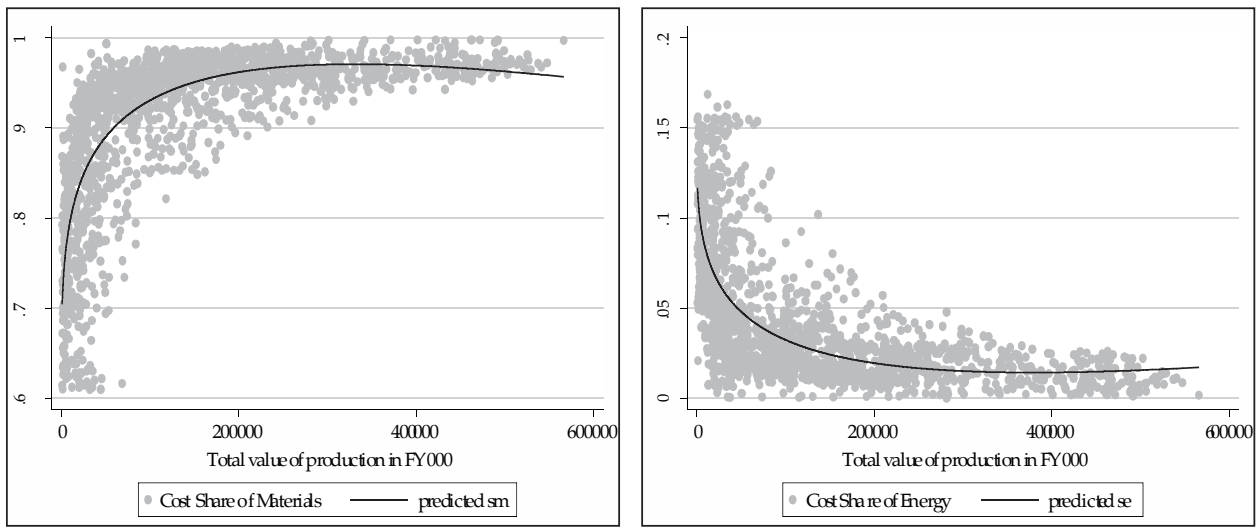

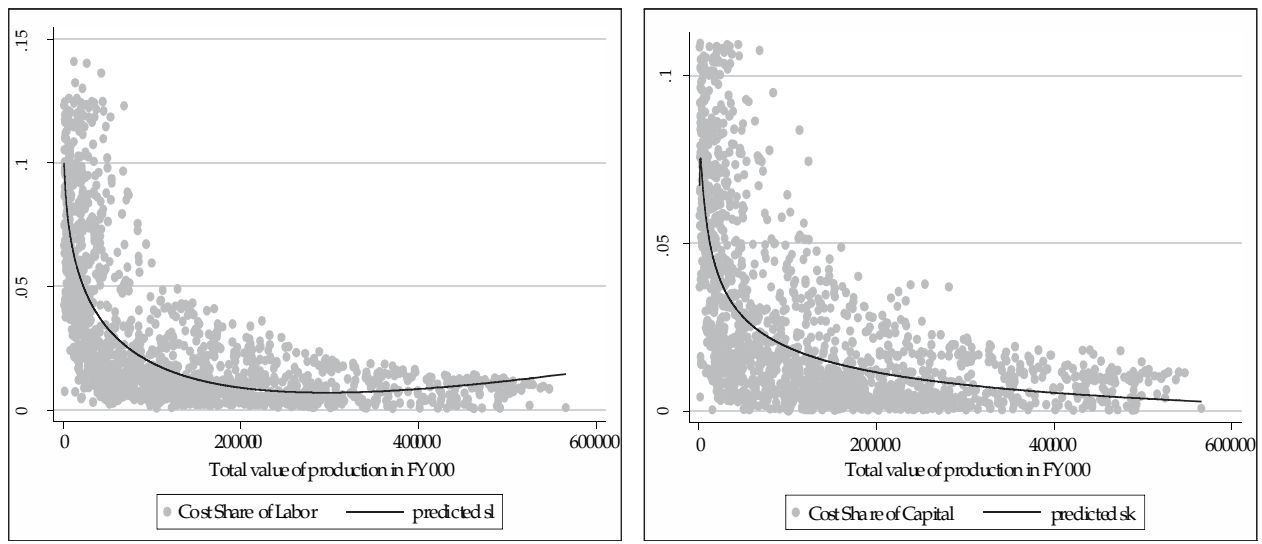

Table 2: Descriptive statistics

\begin{tabular}{lccccc}
\hline Variable & Obs. & Mean & SE & Minimum & Maximum \\
\hline Price of capital & 1,710 & 151.092 & 0.751 & 5.2 & 238.5806 \\
Price of labor & 1,710 & 282.1773 & 4.24 & 13.92157 & 895.5499 \\
Price of material & 1,710 & 18.04708 & 0.336 & 0.010754 & 64.88484 \\
Price of energy & 1,710 & 5.045733 & 0.0545 & 0.0009506 & 13.72417 \\
Quantity & 1,710 & $134,249.1$ & $3,052.5$ & 10 & 566,256 \\
Total cost & 1,710 & $130,756.8$ & $3,003.899$ & 493.5935 & 512,881 \\
\hline
\end{tabular}

\subsection{Results of Nonhomothetic Model}

Table 3 presents the AIC and BIC values for eight models based on the CMI 2005/06 data. Of these eight models, one model with no prior restrictions represents the best-fit model for the data. This selection is based on the AIC and BIC as the model with lower AIC and BIC values is the better model (Everitt, 1998). The translog cost model is a well-behaved concave function because the estimated input cost-shares are positive and the bordered Hessian determinant is negative (Table 4).

Table 3: Model selection criteria

\begin{tabular}{llccc}
\hline Criteria & Model-A & Model-B & Model-C & Model-D \\
\hline AIC & $-21,221.95$ & $-20,538.868$ & $-20,512.214$ & $-19,526.904$ \\
BIC & $-21,140.286$ & $-20,473.537$ & $-20,452.327$ & $-19,472.461$ \\
\hline
\end{tabular}

Table 4: Symmetric bordered Hessian determinant

$$
|H|=\left|\begin{array}{ccccc}
0 & & & & \\
0.00045705 & -0.00072799 & & & \\
0.00025542 & 0.00192687 & -0.00054347 & & \\
0.02365284 & 0.15858417 & 0.14690765 & -2.2158804 & \\
0.08093242 & 0.02102324 & 1.1440833 & 5.4867258 & 0.04512649
\end{array}\right|=-0.000003
$$


Model-A is unrestricted and generates the lowest AIC value (21,221.95). Therefore, the nonhomothetic model best represents the cost structure of the food, beverages and tobacco sectors in Pakistan for the year 2005/06. The CRS, homothetic and homogeneous structures are not true representations of the cost structure of Pakistan's food industries.

This section describes the results of the nonhomothetic model (Table 5). The estimates for nonhomotheticity (output-input $i, i=\mathrm{K}, \mathrm{L}, \mathrm{E}, \mathrm{M}$ ) and nonhomogeneity (squared output) are statistically significant, thereby endorsing the model selection criteria. The coefficients on output-input $i$ indicate a change in the use of input intensity resulting from a variation in output (Zafar \& Ahmed, 2005). The negative sign of the estimates indicates a reduction in the factor input share as output rises. Here, the estimates for nonhomotheticity with respect to capital, energy and labor are negative, which means that the intensities of these inputs fall at higher levels of output. The positive sign on the materials variable depicts the increasing intensity of materials with an increase in output and greater cost-share. This means that, to produce more food, beverages and tobacco items, firms need more raw materials than they do capital, energy and labor.

Table 5: Estimates of nonhomothetic model

\begin{tabular}{|c|c|c|c|c|c|c|c|}
\hline Variable & Estimate & Variable & Estimate & Variable & Estimate & Variable & Estimate \\
\hline Material & 0.492136 & $\begin{array}{l}\text { Capital- } \\
\text { energy }\end{array}$ & 0.001567 & $\begin{array}{l}\text { Capital- } \\
\text { material }\end{array}$ & -0.01197 & Sq-energy & 0.00206 \\
\hline $\mathrm{t}$-value & 30.07 & $\mathrm{t}$-value & 4.57 & $\mathrm{t}$-value & -40.88 & $\mathrm{t}$-value & 5.25 \\
\hline Capital & 0.126956 & $\begin{array}{l}\text { Labor- } \\
\text { energy }\end{array}$ & 0.001737 & $\begin{array}{l}\text { Output- } \\
\text { labor }\end{array}$ & -0.01432 & $\begin{array}{c}\mathrm{Sq}^{-} \\
\text {material }\end{array}$ & 0.03549 \\
\hline $\mathrm{t}$-value & 15.61 & $\mathrm{t}$-value & 5.11 & $\mathrm{t}$-value & -23.76 & $\mathrm{t}$-value & 43.13 \\
\hline Labor & 0.143799 & Output & -0.07117 & $\begin{array}{l}\text { Output- } \\
\text { energy }\end{array}$ & -0.01804 & Cons. & 4.0775 \\
\hline $\mathrm{t}$-value & 18.94 & $\mathrm{t}$-value & -0.35 & $\mathrm{t}$-value & -32.89 & $\mathrm{t}$-value & 3.69 \\
\hline Energy & 0.237196 & Sq-output & 0.043052 & $\begin{array}{l}\text { Output- } \\
\text { capital }\end{array}$ & -0.01162 & & \\
\hline $\mathrm{t}$-value & 33.87 & $\mathrm{t}$-value & 4.62 & $\mathrm{t}$-value & -20.95 & & \\
\hline Sq-capital & 0.003464 & $\begin{array}{l}\text { Material- } \\
\text { labor }\end{array}$ & -0.01817 & $\begin{array}{l}\text { Output- } \\
\text { material }\end{array}$ & 0.043972 & & \\
\hline $\mathrm{t}$-value & 3.41 & $\mathrm{t}$-value & -59.46 & $\mathrm{t}$-value & 30.87 & & \\
\hline Sq-labor & 0.009493 & $\begin{array}{l}\text { Material- } \\
\text { energy }\end{array}$ & -0.00536 & $\begin{array}{l}\text { Capital- } \\
\text { labor }\end{array}$ & 0.006936 & & \\
\hline $\mathrm{t}$-value & 17.49 & $\mathrm{t}$-value & -13.78 & $\mathrm{t}$-value & 13.98 & & \\
\hline
\end{tabular}

The demand for three inputs-capital, labor and energy—is fairly low in this sector. This also indicates the reduced cost-shares of capital, labor and energy at higher levels of output. These results support the nonhomotheticity of the cost function. The parameters estimated for 
material-input $i(i=\mathrm{K}, \mathrm{L}, \mathrm{E})$ are negative, which means that the demand and cost-shares of labor, capital and energy decline as the price of material rises. These estimates are consistent with that of nonhomotheticity. The fixed costshares of each input are represented by labor, capital, energy, and materials. The fixed cost-shares of material and energy are greater than that of capital and labor due to energy crises and uncertainty in the supply of materials. Energy crises compel firms to invest in energy production, while inconsistent supplies encourage firms to stock more material inputs. On the other hand, firms need not pay labor unnecessarily to bind them contractually because high unemployment makes it easier to hire new, qualified, and skilled workers.

The fixed cost-share of capital is lowest among the four inputs because there are fewer capital-intensive industries. All other parameters, $i$, $j(i, j=\mathrm{K}, \mathrm{L}, \mathrm{E}, \mathrm{M})$ in the cost-share equations are positive, which implies expanding cost-shares of the four inputs as input prices rise. The price of material is the largest contributor to the cost-share of material. All four costshare equations show positive second derivatives. Therefore, cost-shares change in the direction of price and output changes.

\subsection{Elasticities}

The elasticities measured here are AES, cross-price elasticity, ownprice elasticity, and the cost elasticity of output. AES measures the substitutability or complementarity between two factor inputs (Uzawa, 1962). This describes the degree of substitution or complementarity between input factors and is measured in percentage terms. Specifically, we define it as the 'percentage change in factor proportion' in response to a one-percent variation in their 'relative prices' (Banda \& Verdugo, 2007). A positive (negative) value of elasticity indicates substitution (complementarity).

Cross-price elasticity is the percentage change in the quantity demanded of a commodity as a result of a one-percent change in the price of its substitute or complement, while own-price elasticity depicts the percentage change in the quantity demanded of a good due to a one-percent variation in its own price. The output elasticity of cost is defined as the responsiveness of total cost resulting from a change in total output. It is also measured in percentage terms and is the ratio of average cost to marginal cost. A small value for the output elasticity of cost shows that the average cost lies above the marginal cost and vice versa. The average cost curve declines while the marginal cost curve has a positive slope (Besanko \& Braeutigam, 2013). 


\subsubsection{Own-Price Elasticities}

Own-price elasticities are presented in Table 6. Own-price elasticities and cost-shares have a very close relationship. An input that has a smaller share of the total cost becomes more elastic and vice-versa. In this study, material has a 90 percent share of the total cost and its own-price elasticity is very low (-0.08663), while energy has a lower share of the total cost and its elasticity approaches 1 . Here, all four elasticities are negative, indicating a negative relationship between the quantity demanded and own prices. Capital and labor have marginal shares in the total cost and both inputs' elasticities are significantly higher than the own-price elasticity of material.

Table 6: ES and own-price elasticities

\begin{tabular}{lccc}
\hline & ES & \multicolumn{2}{c}{ Own-price elasticity } \\
\hline Variable & Value of elasticity & Variable & Value of elasticity \\
\hline Material-energy & 0.8570 & Labor & -0.6510 \\
Material-capital & 0.4877 & Capital & -0.84029 \\
Capital-energy & 2.4578 & Energy & -0.9089 \\
Material-labor & 0.3233 & Material & -0.08663 \\
Labor-capital & 10.011 & & \\
Labor-energy & 2.4064 & & \\
\hline
\end{tabular}

\subsubsection{Elasticities of Substitution}

Table 6 presents six values of ES between inputs. In the food sector, there is a high level of substitution between labor and capital (10.011). This indicates that labor is still important in the food sector and that, during a shortage of capital, labor is a good alternative. This supports a developing country because the sector can absorb more labor.

However, it is worrying that the country's capitalization process is still very slow. Earlier studies on food processing industries (see Battese \& Malik, 1988; S. Kazi et al., 1976; Kazmi, 1981; Kemal, 1981) show very low values (less than unity) of ES of labor for capital. The ES for material indicates substitutability with energy because it approaches $1(0.8570)$. The small estimates of elasticities of material with respect to labor (0.3233) and capital (0.4877) indicate a tendency toward complementarity instead of substitution. Energy can be substituted with capital (2.4578) and labor (2.4064) by a greater amount if the relative price changes. The results indicate that labor is a good substitute for capital and energy. 


\subsubsection{Cross-Price Elasticities}

Cross-price elasticities are presented in Table 7. All the cross-price elasticities are less than 1 . A change in the price of material produces no significant variation in the demand for labor (0.009), capital (0.012) and energy (0.035). Labor and capital are almost equally responsive to variations in each other's prices ( 0.25 and 0.29$)$. The demand for material varies with a change in the prices of labor, capital and energy. The price of energy has the highest effect on demand for material (0.77) and then capital (0.44).

Table 7: Cross-price elasticities

\begin{tabular}{lclc}
\hline Variable & Value of elasticity & \multicolumn{1}{c}{ Variable } & Value of elasticity \\
\hline Material-energy & 0.03559 & Energy-material & 0.7737 \\
Material-capital & 0.01262 & Capital-material & 0.4403 \\
Capital-energy & 0.06362 & Energy-capital & 0.10208 \\
Material-labor & 0.00961 & Labor-material & 0.29189 \\
Labor-capital & 0.2591 & Capital-labor & 0.2977 \\
Labor-energy & 0.09994 & Energy-labor & 0.07156 \\
\hline
\end{tabular}

\subsubsection{Output Elasticity of Cost}

The value of the output elasticity of cost is 0.3329 , which shows that the rise in total cost is less than the increase in total output. Firms do not operate at a minimum level of cost; instead, they produce at a lower level of output than the optimal production level. The average cost curve of the industry lies above the marginal cost curve. The average cost is higher than the minimum level, which indicates the presence of economies of scale. In such circumstances, profitability rises with an increase in production.

\section{Conclusion and Policy Recommendations}

The study estimates the transcendental logarithmic cost function by applying Zellner's iterative methodology to Pakistan's food industry. We estimate Allen's partial ES, cross-price elasticities, own-price elasticities, and output elasticities of cost, which show strong substitution between labor and capital. Contrary to earlier studies (see Battese \& Malik, 1988; S. Kazi et al., 1976; Kazmi, 1981; Kemal, 1981), the substitution of labor for capital has increased in food-processing industries. Capital and energy are good substitutes, but the substitutability between material and capital and between material and energy is significantly lower. 
The share of materials in cost is as high as 90 percent. The own-price elasticities indicate that material input is the least responsive to a change in its own price, while the other three inputs vary in terms of own prices with a change in demand. The cross-price elasticities show that labor and capital are substitutes. The cost elasticity of output demonstrates the presence of economies of scale. Our analysis indicates that the intensity of capital, labor and energy declines as the level of production increases. The intensity of material use increases as output rises.

These findings imply that the strong substitutability between labor and capital can help a country such as Pakistan substitute labor for capital. This, in turn, can have a significant impact on reducing unemployment and poverty. Similarly, that materials have the highest share in costs suggests that its productivity should be enhanced. The major share of the input 'materials' to food industries comes from the agriculture sector. Hence, the cost of food industries depends largely on productivity in the agricultural sector. The cost of food industries and the cost of food could be reduced significantly by adopting modern technologies and making agricultural production more efficient. 


\section{References}

Abdullah, M., \& Osman-Rani, H. (1989). A translog cost estimation of capital-labour substitubility in Malaysian manufacturing sector. Jurnal Ekonomi Malaysia, 20, 43-60.

Banda, H. S., \& Verdugo, L. E. B. (2007). Translog cost functions: An application for Mexican manufacturing [Working paper]. Banco de México.

Barten, A. P. (1969). Maximum likelihood estimation of a complete system of demand equations. European Economic Review, 1(1), 7-73.

Battese, G. E., \& Malik, S. J. (1987). Estimation of elasticities of substitution for CES production functions using data on selected manufacturing industries in Pakistan. Pakistan Development Review, 26(2), 161-177.

Battese, G. E., \& Malik, S. J. (1988). Estimation of elasticities of substitution for CES and VES production functions using firm-level data for food-processing industries in Pakistan. Pakistan Development Review, 27(1), 59-71.

Berndt, E. R., \& Wood, D. O. (1975). Technology, prices, and the derived demand for energy. Review of Economics and Statistics, 57(3), 259268 .

Besanko, D., \& Braeutigam, R. (2013). Microeconomics (5 ${ }^{\text {th }}$ ed.). Wiley.

Chishti, S., \& Mahmood, F. (1991). The energy demand in the industrial sector of Pakistan. Pakistan Development Review, 30(1), 83-88.

Christensen, L. R., Jorgenson, D. W., \& Lau, L. J. (1973). Transcendental logarithmic production frontiers. Review of Economics and Statistics, 55(1), 28-45.

Costantini, V., \& Paglialunga, E. (2014). Elasticity of substitution in capitalenergy relationships: How central is a sector-based panel estimation approach? [Working paper]. http://www.sustainabilityseeds.org/papers/RePec/srt/wpaper/1314.pdf

Diewert, W. (1971). An application of the Shephard duality theorem: A generalized Leontief production function. Journal of Political Economy, 79, 481-507. 
Diwan, R. K., \& Gujarati, D. N. (1968). Employment and productivity in Indian industries - Some questions of the theory and policy. Artha Vijnana, 10(1), 29-67.

Erickson, K. W., Moss, C. B., Nehring, R., \& Ball, V. E. (2003). A translog cost function analysis of US agriculture, 1948-1999. Western Agricultural Economics Association, 64(3), 490-498.

Everitt, B. S. (1998). The Cambridge dictionary of statistics. Cambridge University Press.

Heshmati, A., \& Haouas, I. (2013). Economies of scale in the Tunisian industries. International Journal of Economics and Finance, 5(1), 48-64.

Kazi, S., Khan, Z. S., \& Khan, S. A. (1976). Production relationships in Pakistan's manufacturing industries. Pakistan Development Review, 15(4), 406-423.

Kazi, U. A. (1980). The VES production function: A case study for Indian manufacturing industries. Oxford Economic Papers, 32(1), 163-175.

Kazmi, N. (1981). Elasticities of substitution in the small-scale manufacturing industries of the Punjab (Research Report Series No. 122). Pakistan Institute of Development Economics.

Kemal, A. R. (1981). Substitution elasticities in the large-scale manufacturing industries of Pakistan. Pakistan Development Review, 20(1), 1-36.

Khalil, A. (2005). A cross section estimate of translog production function: Jordanian manufacturing industry. Topics in Middle Eastern and North African Economies, 7, 1-14. http://www.luc.edu/orgs/meea/volume7/khalil.pdf

Kmenta, J., \& Gilbert, R. F. (1968). Small sample properties of alternative estimators of seemingly unrelated regressions. Journal of the American Statistical Association, 63(324), 1180-1200.

Krishnapillai, S., \& Thompson, H. (2012). Cross section translog production and elasticity of substitution in US manufacturing industry. International Journal of Energy Economics and Policy, 2(2), 50-54.

Mahmood, T., Ghani, E., \& Din, M. (2006). Efficiency of large-scale manufacturing in Pakistan: A production frontier approach. Pakistan Development Review, 45(4), 689-700. 
McFadden, D. (1963). Constant elasticities of substitution production functions. Review of Economic Studies, 30(2), 73-83.

Pakistan, Federal Board of Revenue. (2014). Taxpayer's facilitation guide. Government of Pakistan.

Pakistan, Ministry of Finance. (2006). Pakistan Economic Survey 2005/06. Government of Pakistan.

Pakistan, Ministry of Finance. (2019). Pakistan Economic Survey 2018/19. Government of Pakistan.

Rushdi, A. A. (1982). Factor substitutability in the manufacturing industries of Bangladesh: An application of the translog cost model. Bangladesh Development Studies, 10(2), 85-105.

Segal, D. (2003). A multi-product cost study of the US life insurance industry. Review of Quantitative Finance and Accounting, 20, 1-33.

Sterner, T. (1989). Factor demand and substitution in a developing country: Energy use in Mexican manufacturing. Scandinavian Journal of Economics, 91, 723-739.

Uzawa, H. (1962). Production functions elasticities of substitution. Review of Economic Studies, 29(4), 291-299.

Zafar, S., \& Ahmed, E. (2005). Evidence on allocative efficiency and elasticities of substitution in the manufacturing sector of Pakistan. Pakistan Development Review, 44(4, Part 2), 795-803.

Zellner, A. (1962). An efficient method of estimating seemingly unrelated regressions and tests for aggregation bias. Journal of the American Statistical Association, 57(298), 348-368. 